\title{
ARENA KAJIAN ANTROPOLOGI HUKUM
}

\author{
Nama $\quad$ :Suci Rahmadona \\ Email : : sucirahmadona76@yahoo.com \\ Kelas $\quad: 1 \mathrm{H} 8 /$ Reguler 2 \\ Perguruan Tinggi : Universitas Ekasakti Padang
}

\section{BAB I}

PENDAHULUAN

\section{A. Latar Belakang}

Antropologi secara etimologis berasal dari bahasa Yunani. Kata Anthropos berarti mansia dan logos berarti ilmu pengetahuan. Jadi, antropologi adalah ilmu yang mempelajari manusia. Oleh karena itu antropologi didasarkan pada kemajuan yang telah dicapai ilmu pengetahuna sebelumnya. Pitirim Sorokim mengatakan bahwa Sosiologi adalah suatu ilmu yang mempelajari hubungan dan pengaruh timbal balik antara aneka macam gejala-gejala sosial (gejalaekonomi dengan agama, keluarga dengan moral, hukum dengan ekonomi) dengan gejala lainnya (nonsosial). Berbeda dengan pendapat Rouceke dan Warren yang mengatakan bahwa Sosiologi adalah ilmu yang mempelajarihubungan manusia dengan kelompokkelompok. Berdasarkan uraian di atas, maka Sosiologi merupakan ilmu sosialyang objeknya adalah masyarakat sebagai ilmu. Ia berdiri sendiri karena telah memiliki unsur ilmu pengetahuan. Dalam ilmu antropologi hukum dipelajari juga mengenai Peran, Status atau kedudukan, Nilai, Norma dan juga Budaya atau kebudayaan. Kesemuanya ini merupakan hal-hal yang sangat erat kaitannya dengan ilmu antropologi hukum. 


\section{B. Maksud dan Tujuan}

Penulisan makalah ini saya buat adalah untuk:

1. Memenuhi Ujian Akhir Semester (UAS) Matakuliah Antropologi Hukum;

2. Memberikan gambaran umum mengenai arena kajian antropologi hukum;

3. Menambah wawasan baru bagi saya, serta sebagaiarahan agar saya sebagai Mahasiswa dapat mengkorekasikan hubungan Natropologi hukum dengan nilai, norma san kebudayaan serta mengetahui bagaimana implementasi Antrropologi Hukum dalam kehidupan bermasyarakat, berbangsa dan bernegara. 


\section{BAB II}

\section{PEMBAHASAN}

\section{PENGERTIAN ANTROPOLOGI HUKUM}

Antropologi berasal dari bahasa Yunani, Antropos yang artinya manusia dan Logos yang artinya ilmu. Ilmu tentang hayati terdiri dari:

1. Paleo Antropologi, yaitu mempelajari tentang asal usul manusia dan perkembangannya. Metode yang digunakan dengan penggalian fosil-fosil. Bagian yang dipelajari adalah organ-organ dalam tubuh.

2. Antropologi Fisik, yaitu mempelajari bentuk-bentuk manusia, baik bagian dalam maupun bagian luar tubuh. Tujuannya mempelajari corak ragam manusia.

Jadi, Antropologi Hukum adalah kajian antropologi terhadap makna sosial dari dan pentingnya hukum dengan menelaah bagaimana hukum dibuat termasuk bagaimana konteks sosial pembuatan hukum tersebut, bagaimana hukum mempertahankan dan mengubah institusi sosial lainnya, dan bagaimana hukum membangun perilaku sosial.

\section{PEMBAGIAN ANTROPOLOGI}

Antropologi mempelajari perkembangan kehidupan manusia dan budayanya, dengan cabang-cabang ilmu, diantaranya; ilmu PraSejarah untuk mempelajari kehidupan asal usul manusia, dan untuk mengetahui ragam bahasa manusia maka harus mempelajari Etnolinguistik, sedangkan ilmu yang mempelajari cara manusia berbangsa dan berbudaya disebut Etnologi.

Antropologi adalah studi ilmu yang mempelajari tentang manusia dari Aspek Budaya, Perilaku, Nilai, Keanekaragaman, dan lainnya. Antropologi terbagi dalam: Antropologi 
Ekonomi, Antropologi Politik, Antropologi Pendidikan, dan Antropologi Hukum. Antropologi Hukum merupakan ilmu yang mempelajari manusia dengan kebudayaan, khususnya di bidang Hukum, atau ilmu tentang Manusia dalam kaitannya dengan Kaidah-kaidah sosial yang bersifat Hukum.

\section{BUDAYA DAN KEBUDAYAAN HUKUM}

Kebudayaan hukum adalah kekuasaan yang digunakan oleh penguasa untuk mengatur masyarakat agar tidak melanggar kaidah-kaidah sosial yang telah ada dalam masyarakat. Hukum diperlukan meski telah ada kaidah atau norma dalam masyarakat, agar terdapat keteraturan dalam kehidupan manusia melalui hukum tertulis dengan sanksi yang nyata disamping norma dan kaidah yang sanksinya lebih bersifat sosial atau akhirat.

Sebagai Ilmu Pengetahuan, Antropologi Hukum dicirikan oleh 3 (tiga) hal yaitu adanya: Objek, Metode, dan Sistem. Antropologi Hukum sebagai ilmu pengetahuan yang merupakan spesialisasi dari Antropologi Budaya, memiliki karakter:

1. Antropologi Hukum, adalah Ilmu pengetahuan (logos) tentang Manusia (antropos) yg berhubungan dengan Hukum;

2. Manusia, adalah manusia yg hidup bermasyrakat, masyarakat yg masih sederhana budayanya (primitif) dan yg sudah Maju (modern);

3. Budaya adalah Budaya Hukum, yaitu segala bentuk perilaku budaya manusia yg mempengaruhi Masalah Hukum. Budaya adalah milik bersama yang perlu dipertahankan atau dilestarikan.

Budaya hukum adalah tanggapan masyarakat terhadap suatu perbuatan yang dianggap baik, yang hal ini juga bergantung pada sikap penegak hukum. Nilai budaya atau Postulat adalah 
nilai yang ada dalam masyarakat modern dan masyarakat sederhana yang dinilai baik atau dipertahankan. Masalah Hukum tidaklah hanya pada masalah hukum yang normatif (undangundang), atau masalah hukum yang merupakan pola perilaku yg sering terjadi (hukum adat ), tetapi juga masalah budaya terhadap suatu masalah Hukum, dikarenakan adanya Faktor Budaya yang mempengaruhinya, yaitu:

1. Faktor-faktor Budaya yg melatar belakangi Masalah Hukum

Contoh: cara menyelesaikan masalah perselisihan dikalangan Orang Batak, tidak sama dengan orang Minang, Jawa, Bali, Maluku dan lainya;

2. Cara-cara tersebut menjadi objek perhatian Antropologi Hukum.

\section{ARENA KAJIAN ANTROPOLOGI HUKUM}

Kajian Antropologi Hukum adalah menggali norma dan nilai-nilai dalam masyarakat. Arena Antropologi Hukum mempelajari manusia dan budaya hukum, karenanya kaidah sosial yang tidak bersifat hukum bukanlah sasaran pokok penelitian Antropologi Hukum.

Norma/kaidah menurut Antropologi Hukum pola ulangan perilaku dalam masyarakat. Norma/Kaidah adalah nilai dasar yang ada dalam masyarakat yang dapat mengukur perilaku manusia agar dapat menilai mana perbuatan benar dan mana yang tidak benar. Norma memiliki aspek hukum ketika aparat menjatuhkan sanksi karena ada perbuatan yang menyimpang atau melanggar hukum. Sanksi bersifat positif seperti dengan membayar denda atau kerja sosial, dan sanksi bersifat negatif seperti hukuman badan atau dikucilkan. Hukum muncul dari peradaban manusia, dimana ada 2 orang atau lebih di situ ada hukum. 


\section{SIFAT KEILMUAN ANTROPOLOGI HUKUM}

1. Antropologi Hukum tidak membatasi pandangan pada kebudayaan tertentu (studi perbandingan).

2. Antroplogi Hukum, mempelajari masyarakat sebagai suatu keseluruhan yang utuh, dimana bagian-bagiannya saling bertautan.

3. Antropologi Hukum Modern tidak memusatkan perhatian hanya pada kekuatan sosial dan hal superorganis.

4. Antropologi Hukum memandang masyarakat secara Dinamis, sehingga peranan sosial dan Hukum tidak terbatas mempertahankan status quo.

5. Antropologi Hukum termasuk ilmu Hukum yang empiris.

\section{HUBUNGAN ANTROPOLOGI HUKUM DENGAN ILMU SOSIAL LAINNYA}

Hubungan antropologi hukum dengan ilmu sosial lainnya sebagai berikut:

1. Antropologi Hukum dengan Hukum Adat;

2. Antropologi Hukum dengan Sosiologi;

3. Antropologi Hukum dengan Etnologi;

4. Antropologi Hukum dengan Religi;

5. Antropologi Hukum dengan Psikologi Sosial.

\section{CARA MEMPELAJARI ANTROPOLOGI HUKUM}

1. Metode Historis, yaitu mempelajari perilaku manusia melalui sejarah kebiasaan yang ada dalam masyarakat menjadi adat, berkembang menjadi hukum adat, yang dipertahankan oleh penguasa lalu menjelma sebagai hukum negara. 
2. Metode Normatif Eksploratif, yaitu mempelajari perilaku manusia dan budaya hukumnya melalui norma hukum yang sudah ada / yang dikehendaki, bukan sebatas norma hukum yang berlaku, melainkan melihat perilaku manusia barulah mengetahui hukum yang akan diterapkan.

3. Metode Deskriptif Perilaku, yaitu mempelajari perilaku manusia dan budaya hukumnya melalui hukum yang nyata tanpa melihat aturan hukum ideal. Metode ini sempurna apabila disertai metode kasus.

4. Metode Studi Kasus, yaitu pendekatan Antropologi Hukum dengan mempelajari kasus-kasus yang terjadi terutama kasus perselisihan. 


\section{BAB III}

\section{PENUTUP}

Antropologi adalah ilmu yang mempelajari manusia. Oleh karena itu antropologi didasarkan pada kemajuan yang telah dicapai ilmu pengetahuan sebelumnya. Pengertian Antropologi dapat dilihat dari 2 sisi yaitu Antropologi sebagai ilmu pengetahuan artinya bahwa Antropologi merupakan kumpulan pengetahuan-pengetahuan tentang kajian masyarakat dan kebudayaan yang disusun secara sistematis atas dasar pemikiran yang logis dan pengertian Antropologi yang kedua adalah cara-cara berpikir untuk mengungkapkan realitas sosial dan budaya yang ada dalam masyarakat dengan prosedur dan teori yang dapat dipertanggungjawabkan kebenarannya secara ilmiah.

Setelah di kaji kita dapat mengemukakan hasilnya bahwa manfaat di dalam antropologi hukum sangat luas. Antropologi hukum telah memberikan kontribusi yang sangat besar bagi perkembangan ilmu hukum. Kesimpulan yang dapat diambil adalah dimana pun kita berada, kita tidak akan pernah jauh dari hukum selama kita berada di Negara hukum. 


\section{DAFTAR PUSTAKA}

Gokma Toni Parlindungan S, Asas Nebis In Idem Dalam Putusan Hakim Dalam Perkara Poligami Di Pengadilan Negeri Pasaman Sebagai Ceriminan Ius Constitutum, Volume 2, Nomor 1, 2020.

Gokma Toni Parlindungan S, Pengisian Jabatan Perangkat Nagari Pemekaran Di Pasaman Barat Dalam Rangka Pelaksanaan Otonomi Daerah, Ensiklopedia Of Journal, Vol 1 No 2 Edisi 2 Januari 2019,

Harniwati, Peralihan Hak Ulayat Menurut Undang-Undang Nomor 18 Tahun 2004, Volume 1, Nomor 3, 2019.

Jasmir, Pengembalian Status Hukum Tanah Ulayat Atas Hak Guna Usaha, Soumatera Law Review, Volume 1, Nomor 1, 2018.

Jumrawarsi Jumrawarsi, Neviyarni Suhaili, Peran Seorang Guru Dalam Menciptakan Lingkungan Belajar Yang Kondusif, Ensikopedia Education Review, Vol 2, No 3 (2020): Volume 2 No.3 Desember 2020

Mia Siratni, Proses Perkawinan Menurut Hukum Adatdi Kepulauan Mentawai Di Sebelum Dan Sesudah Berlakunya Undang-Undang Nomor 1 Tahun 1974 Tentang Perkawinan, Ensiklopedia Of Journal, Vol 1 No 2 Edisi 2 Januari 2019,

Remincel, Dimensi Hukum Pelanggaran Kecelakaan Lalu Dan Angkutan Jalan Lintas Di Indonesia, Ensiklopedia Social Review, Volume 1, Nomor 2, 2019.

R Amin, B Nurdin, Konflik Perwakafan Tanah Muhammadiyah di Nagari Singkarak Kabupaten Solok Indonesia 2015-2019, Soumatera Law Review, Volume 3, Nomor 1, 2020. 